\title{
Feasibility of Parylene Coating for Planar Electroporation Copper Electrodes
}

\author{
Vitalij NOVICKIJ ${ }^{1 *}$, Aleksandr TABAŠNIKOV ${ }^{2}$, Stewart SMITH ${ }^{2}$, Audrius GRAINYS ${ }^{1}$, \\ Jurij NOVICKIJ ${ }^{1}$, Sonata TOLVAIŠIENE ${ }^{3}$, Svetlana MARKOVSKAJA ${ }^{4}$ \\ ${ }^{1}$ Institute of High Magnetic Fields, Vilnius Gediminas Technical University, Naugarduko g. 41, LT-03227 Vilnius, \\ Lithuania \\ ${ }^{2}$ Scottish Microelectronics Centre, University of Edinburgh, King's Building, EH9 3JF Edinburgh, United Kingdom \\ ${ }^{3}$ Department of Electrical Engineering, Vilnius Gediminas Technical University, Naugarduko g. 41, LT-03227 Vilnius, \\ Lithuania \\ ${ }^{4}$ Laboratory of Mycology, Nature Research Centre, Žaliuju ežeru g. 49, LT-08406 Vilnius, Lithuania \\ cross $^{\text {ref }}$ http://dx.doi.org/10.5755/j01.ms.23.2.14953
}

Received 11 May 2016; accepted 02 September 2016

\begin{abstract}
This paper is focused on the feasibility study of parylene as a biocompatible coating for planar electroporation microelectrodes. The planar parallel and the circular interdigitated electrodes are applied in the analysis. The electrodes feature $100 \mu \mathrm{m}$ width with a $300 \mu \mathrm{m}$ gap between anode and cathode. The parylene coating thickness was varied in the $250 \mathrm{~nm}-2 \mu \mathrm{m}$ range. The resultant electric field distribution evaluation has been performed using the finite element method. The electrodes have been applied in electroporation experiments with Saprolegnia parasitica. For reference the additional experiments using conventional electroporation cuvette $(1 \mathrm{~mm}$ gap) have been performed. It has been determined that the parylene coating with hydrophobic properties has limited applicability for the passivation of the planar electroporation electrodes.

Keywords: microelectrodes, pulsed electric field, biological cells.
\end{abstract}

\section{INTRODUCTION}

Electroporation is a biological cell treatment method based on the application of the pulsed electric field to induce reversible and non-reversible changes in the cell membrane permeability [1-4]. Conventional electroporation includes a pulsed power generator for high voltage pulse formation and a cuvette for biological cells with integrated electrodes, where a high intensity and defined duration electric field is exerted $[5,6]$. In this case the design of the electrodes usually consists of two parallel metal plates (anode and cathode) in direct contact with the cell medium, where a uniform electric field is generated [7]. Such configuration is typical for many electroporation setups [8-11]. Depending on the physical o biological treatment parameters such as pulse duration, amplitude, polarity, repetitive frequency, waveform or cell geometry [12-15] the electroporation effect can be reversible and irreversible [1, 16-18]. Both outcomes are desirable in biotechnology and have found vast applications in cancer treatment (electrochemotherapy), DNA transfer (genetic engineering), food processing (sterilization) and many others $[15,19-21]$.

Since the electroporation phenomenon is popular biomedical technique, the biophysics of the process is studied in detail. The research for possibility to observe the electroporation process in real-time on a microscope stage has resulted in the increased interest in microfluidic systems [22-24]. Different planar configurations of the electrodes have been proposed, where planar parallel strip structures and interdigitated electrode configurations are common [25-27]. However, various problems arise, such as the spatial non-uniformity of the electric field

\footnotetext{
${ }^{*}$ Corresponding author. Tel.: +370-67-410482.

E-mail address: vitalij.novickij@vgtu.lt (V. Novickij)
}

distribution, complexity of electrode fabrication, biological compatibility issues, and the voltage breakdown occurrence between the electrodes [28]. As a result planar electroporation in the present form is limited due to the complexity, price and the electrodes fabrication challenges [29].

At the same time parylene is frequently used as a substrate for microfluidic devices and has proven to have good biomedical compatibility when used as a passivation layer for metals even for in vivo applications [30-32]. Nevertheless, the number of works focusing on the development of planar microelectrodes for electroporation and featuring passivation of the electrode surface with parylene is low.

The main reasons can be based on the problems of parylene adhesion to the surface of microfluidic devices and the negative influence of parylene coating on the distribution of the electric field $[33,34]$. On the other hand introduction of parylene layer to planar electroporation could potentially enable application of non-biocompatible materials (such as copper) [35], thus simplify the fabrication process and reduce the total cost of the device [36].

In this work we present the experimental feasibility study of the parylene as a biocompatible coating [37] for planar electroporation. The influence of parylene layer thickness on the electric field distribution and the respective parameters of electroporation are determined.

\section{MATERIALS AND METHODS}

\subsection{Electrodes}

Planar parallel strip and circular interdigitated microelectrode [38] configurations are applied in the study. The microelectrodes have been fabricated using laser 
etching (LPKF, USA) on a FR-4 glass epoxy substrate based copper board (LPKF, USA). The copper thickness was $18 \mu \mathrm{m}$. The gap between electrode fingers was $300 \mu \mathrm{m}$. The surface of the chips has been covered with parylene in the parylene deposition tool (SCS 2010 Labcoter, USA). As parylene is known to have conformal coating properties, coating thickness was in a range of $250 \mathrm{~nm}$ to $2 \mu \mathrm{m}$, which was a reasonable trade-off between dielectric effect on electric field (refer to Fig. 2) and aspect ratio of polymer to coated copper features. The coating thickness has been measured using spectroscopic reflectometer (Nanometrics NanoSpec 3000, USA) on the reference samples for each batch. The structure of the electrodes is shown in Fig. 1.

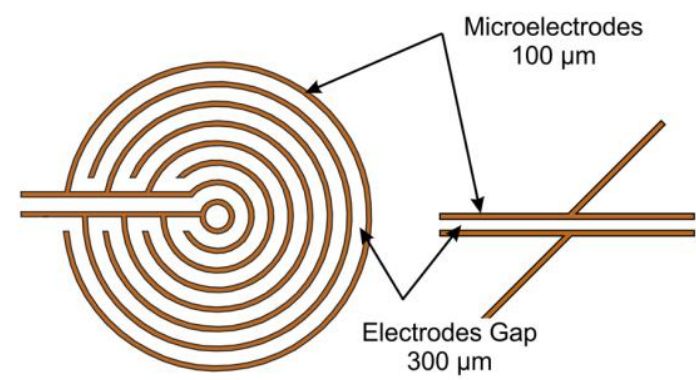

a

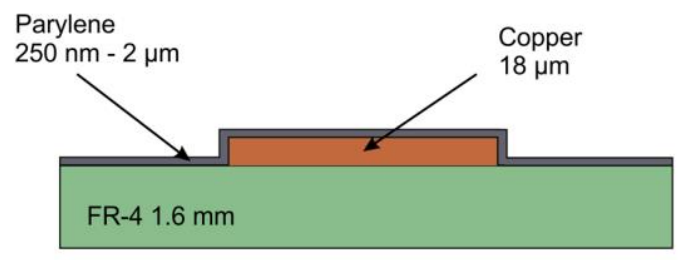

b

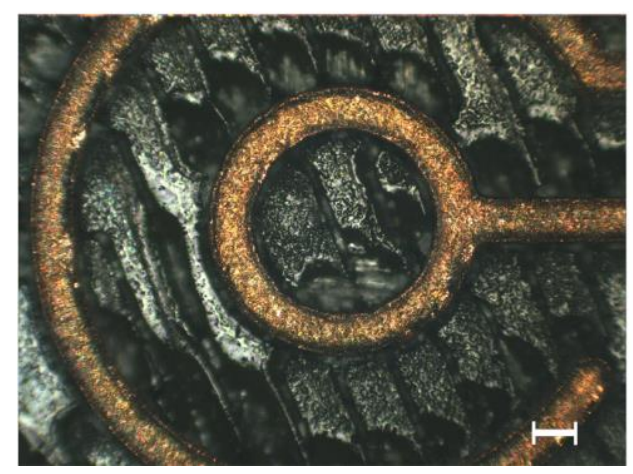

Fig. 1. a-configuration of the circular interdigitated and parallel strip planar microelectrodes; $b$-fabricated layer structure of one of the fingers of the microelectrodes; $\mathrm{c}-$ microphotograph of the laser etched electrode fingers, where the scale mark represents $100 \mu \mathrm{m}$

As it can be seen in Fig. 1 the application of interdigitated electrode configuration allows increasing the number of separate experimental instances proportionally to the number of equivalent pairs of anodes and cathodes. In order to evaluate the resultant electric field distribution between planar fingers and estimate the influence of parylene layer the finite element method (FEM) analysis has been applied (COMSOL Multiphysics, Sweden).

\subsection{FEM analysis}

The model of the microelectrodes has been constructed in the $2 \mathrm{D}$ plane. The parameters that were used are summarized in Table 1 . In the simulation a $100 \mathrm{~V}$ voltage has been applied to the electrode contacts in order to generate high intensity electric field. The results of the FEM simulation for the parallel strip microelectrodes are shown in Fig. 2 a, b. As it can be seen in Fig. 2 a parallel strip electrode configuration allows generating a spatially non-uniform electric field.

Table 1. FEM model parameters

\begin{tabular}{|c|c|}
\hline Parameter & Value \\
\hline Electrode width, $\mu \mathrm{m}$ & 100 \\
\hline Electrode gap, $\mu \mathrm{m}$ & 300 \\
\hline FR-4 relative permittivity & 4.2 \\
\hline Buffer relative permittivity & 71 \\
\hline Parylene relative permittivity & 2.65 \\
\hline Applied voltage, $V$ & 100 \\
\hline
\end{tabular}

There are reports for possibilities of application of non-uniform electric fields in electroporation, however spatial uniformity is desirable. In Fig. 2 a the $>90 \%$ homogeneity region is marked with a dot rectangle. In order to estimate the effect of parylene on the electric field distribution the parylene layer has been introduced to the simulation as shown in Fig. $1 \mathrm{~b}$. The magnitude of the electric field in the gap between electrodes has been estimated at a fixed height $(z=5 \mu \mathrm{m})$. The results for different thicknesses of the parylene coating are presented in Fig. 2 b.
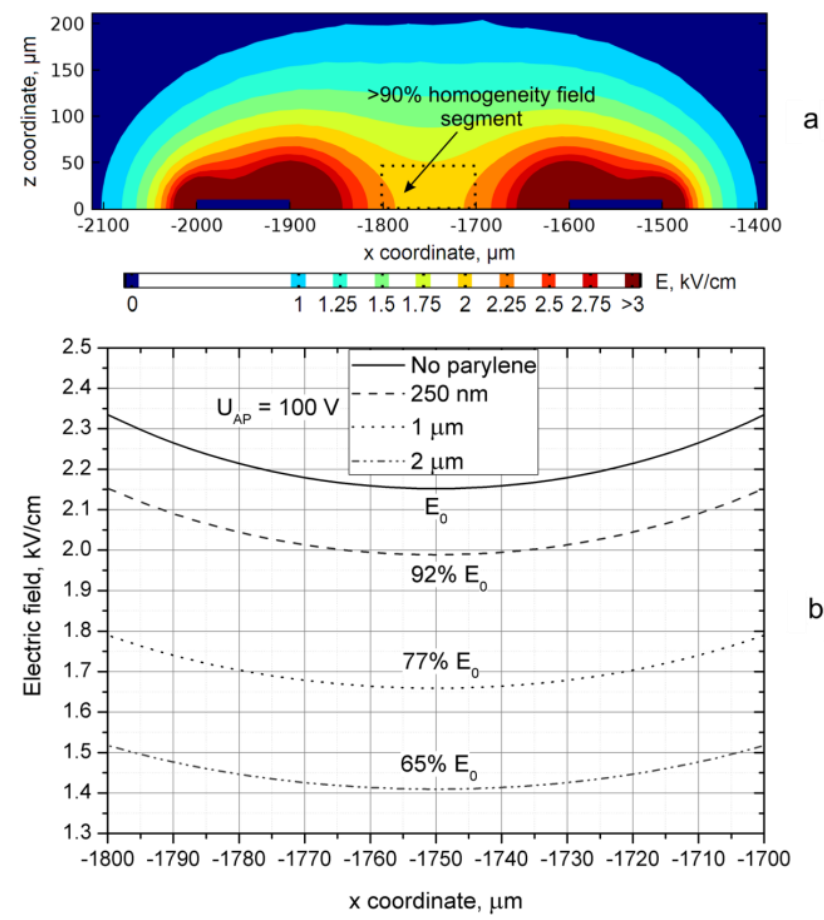

Fig. 2. a-FEM analysis of the XZ plane electric field distribution in the parallel strip electrode structure; $b$-influence of parylene layer on the distribution of the electric field in the $>90 \%$ homogeneity region between electrode fingers, $\mathrm{z}=5 \mu \mathrm{m}$

The FEM simulation results indicate that the magnitude of the electric field is reduced up to $65 \% \mathrm{E}_{0}\left(\mathrm{E}_{0}-\right.$ electric field amplitude generated without parylene layer) for the $2 \mu \mathrm{m}$ parylene coating. The same tendency is observed when the interdigitated electrodes are applied, thus the 
results are not shown.

\subsection{Pulse delivery setup}

The square wave electrical pulse generator developed in High Magnetic Field Institute (Vilnius, Lithuania) has been applied in the study [11]. The setup is capable of delivering repetitive $1 \mu \mathrm{s}-10 \mathrm{~ms} 0-1 \mathrm{kV}$ square wave and bipolar pulses. The maximum current is internally limited to $100 \mathrm{~A}$. The electrodes have been connected directly as a load of the generator. The additional experiments using conventional electroporation cuvette have been performed (BTX, Cuvette plus ${ }^{\mathrm{TM}}$, Nr. 610, San Diego, USA) to provide reference measurements.

The waveform of the pulse is shown in Fig. 3.

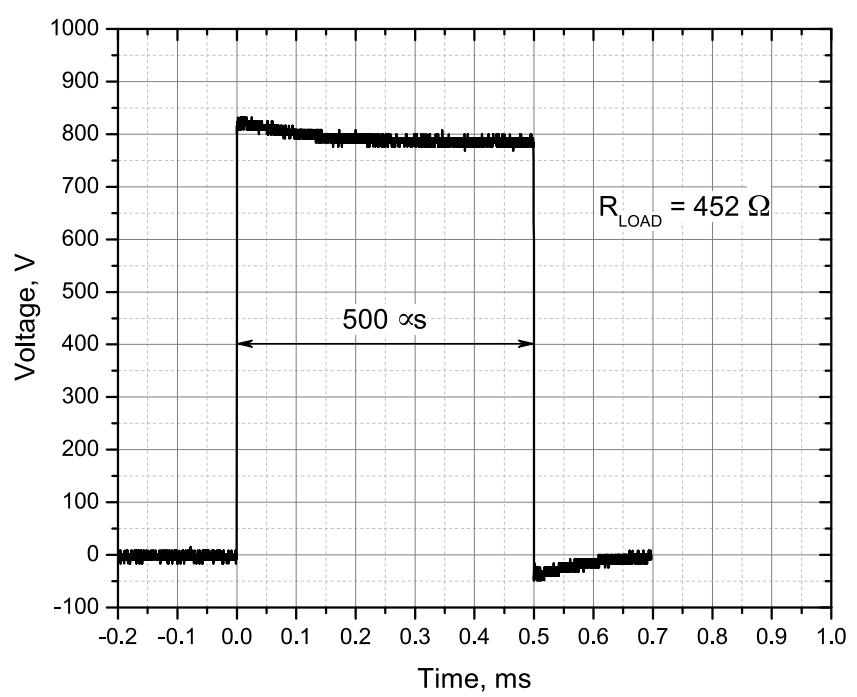

Fig. 3. The waveform of the electrical pulse

During experiments the charging voltage has been varied in the $0.1-0.8 \mathrm{kV}$ range. Based on the FEM simulation results the charging voltage has been adjusted for each applicator depending on the parylene layer thickness and electrodes type. The $1-8 \mathrm{kV} / \mathrm{cm} 20$ pulses bursts $(1 \mathrm{~Hz})$ have been applied in the experiments.

\subsection{Biological cells}

The freshwater mold Saprolegnia parasitica has been used in the experiments. The specimens have been isolated from the water samples collected in a freshwater pool (Vilnius, Verkiai park). The colony has been incubated for several days at room temperature using the hemp seed as bait. Later the fragments of hyphae and the reproductive spores were cut from colony and a suspension using distilled water as a base has been formed. For the conventional electroporation the samples of $80 \mu \mathrm{l}$ have been used for each instance, while the $5 \mu \mathrm{l}$ samples were used for the planar electroporation.

\section{EXPERIMENT}

The experiments using the $250 \mathrm{~nm}$ and $2 \mu \mathrm{m}$ parylene coating electrodes and the conventional BTX cuvette have been performed. The electroporation effect has been evaluated by the morphological analysis of the cell membrane integrity. The number of the cells with the compromised cell membrane integrity was estimated as a percentage to the total number of the cells that were analysed in the experimental instance during the light microscopy. The summary of the results and the microphotograph of the $S$. parasitica with the compromised membrane integrity are shown in Fig. 4.

As it can be seen in Fig. 4 the electroporation can induce irreversible damage to the cell membrane (6$8 \mathrm{kV} / \mathrm{cm}, 20$ pulses, $1 \mathrm{~Hz}$ ). However during experiments we were not able to detect any statistically significant changes in the morphology of the cells when the planar electrodes with parylene coating were used. On the opposite the conventional electroporation procedure resulted in up to $20 \%$ of the cells being damaged.

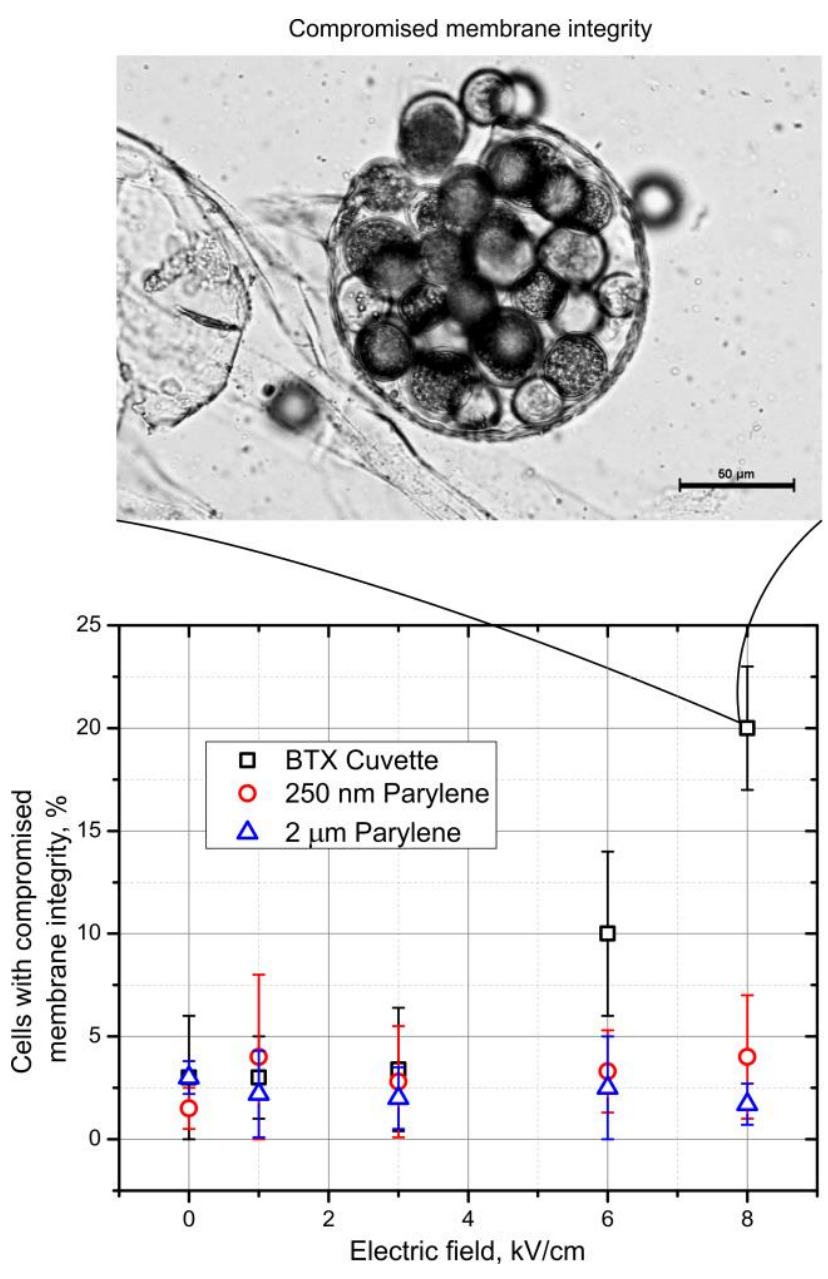

Fig. 4. The microphotograph of the $S$. parasitica with compromised membrane integrity after electroporation and the fraction of the damaged cells compared to the total number of cells; the scale mark represents $50 \mu \mathrm{m}$

It has been concluded that the result was influenced by the hydrophobic properties of the parylene coating, resulting in a higher cells spatial $\mathrm{z} \gg 5 \mu \mathrm{m}$ position under the coverslip, thus the induced transmembrane potential was not high enough for the permeabilization phenomenon to occur.

\section{DISCUSSION AND CONCLUSION}

The planar electroporation electrodes have been applied in the study and the feasibility of the parylene coating has been analysed. It has been shown that the parylene coating results in the reduction of the peak 
electric field (up to $65 \% \mathrm{E}_{0}$ in the $2 \mu \mathrm{m}$ coating case). The experimental data indicated that the hydrophobic properties of the parylene that was deposited according to the described methodology negatively influence the electroporation efficacy. We were not able to acquire any statistically significant morphological changes in the $S$. parasitica, while the reference experiments using the conventional electroporation cuvette at the same conditions were successful. It has been concluded that the induced transmembrane potential was not high enough for the permeabilization phenomenon to occur due to the higher cells spatial $\mathrm{z} \gg>5 \mathrm{~m}$ position under the coverslip.

The next step and the object of the future works for a potential solution to this issue would be the treatment of the parylene coating by the oxygen plasma, thus removing a proportion of the coating thickness and rendering the surface of parylene coating to hydrophilic. This would require accordingly the deposition of a higher thickness of the parylene layer. Such configuration could potentially enable application of the non-biocompatible materials (such as copper) for electroporation experiments, thus simplify the fabrication process and reduce the total cost of the device, compared to the platinum or gold electrodes.

\section{Acknowledgments}

This work was supported by the Research Council of Lithuania towards the Future Technologies Programme project Nr. LAT-02/2016.

\section{REFERENCES}

1. Davalos, R.V., Mir, L.M., Rubinsky, B. Tissue Ablation with Irreversible Electroporation Annals of Biomedical Engineering 33 (2) 2005: pp. 223-231.

2. Kotnik, T., Frey, W., Sack, M., Haberl Meglič, S., Peterka, M., Miklavčič, D. Electroporation-based Applications in Biotechnology Trends in Biotechnology 33 (8) 2015: pp. 480 - 488.

3. Deng, J., Schoenbach, K.H., Stephen Buescher, E., Hair, P.S., Fox, P.M., Beebe, S.J. The Effects of Intense Submicrosecond Electrical Pulses on Cells Biophysical Journal 84 (4) 2003: pp. 2709-2714.

4. Gehl, J. Electroporation: Theory and Methods, Perspectives For Drug Delivery, Gene Therapy and Research. Acta Physiologica Scandinavica 177 (4) 2003: pp. 437-447. https://doi.org/10.1046/j.1365-201X.2003.01093.x

5. Lynch, P.T., Davey, M.R. Electrical Manipulation of Cells Boston, MA: Springer US; 1996. https://doi.org/10.1007/978-1-4613-1159-1

6. Yarmush, M.L., Golberg, A., Serša, G., Kotnik, T., Miklavčič, D. Electroporation-Based Technologies for Medicine: Principles, Applications, and Challenges Annual Review of Biomedical Engineering 16 (1) 2014: pp. $295-320$.

7. Mahnič-Kalamiza, S., Kotnik, T., Miklavčič, D. Educational Application for Visualization and Analysis of Electric Field Strength in Multiple Electrode Electroporation BMC Medical Education 12 2012: pp. 102.

8. Reberšek, M., Miklavcic, D., Bertacchini, C., Sack, M. Cell Membrane Electroporation-Part 3: the Equipment IEEE Electrical Insulation Magazine 30 (3) 2014: pp. 8 18.

9. Novickij, V., Grainys, A., Novickij, J., Lucinskis, A.
Programmable Pulsed Magnetic Field System for Biological Applications IEEE Transactions on Magnetics 50 (11) 2014: pp. $1-4$. https://doi.org/10.1109/TMAG.2014.2323336

10. Rebersek, M., Miklavcic, D. Advantages and Disadvantages of Different Concepts of Electroporation Pulse Generation Automatika 52 (1) 2011: pp. 12-19.

11. Grainys, A., Novickij, V., Novickij, J. High-power Bipolar Multilevel Pulsed Electroporator Instrumentation Science \& Technology 44 (1) 2016: pp. 65-72. https://doi.org/10.1080/10739149.2015.1060607

12. Flisar, K., Puc, M., Kotnik, T., Miklavcic, D. Cell Membrane Electropermeabilization With Arbitrary Pulse Waveforms IEEE Engineering in Medicine and Biology Magazine: the Quarterly Magazine of the Engineering in Medicine \& Biology Society 22 (1) 2003: pp. 77-81.

13. Golzio, M., Mora, M.P., Raynaud, C., Delteil, C., Teissié, J., Rols, M.P. Control by Osmotic Pressure of Voltage-Induced Permeabilization and Gene Transfer in Mammalian Cells Biophysical Journal 74 (6) 1998: pp. 3015-3022.

14. Rebersek, M., Faurie, C., Kanduser, M., Corović, S., Teissié, J., Rols, M.P., Miklavcic, D. Electroporator with Automatic Change of Electric Field Direction Improves Gene Electrotransfer In-Vitro Biomedical Engineering Online 6 2007: pp. 25. https://doi.org/10.1186/1475-925X-6-25

15. Arena, C.B., Sano, M.B., Rylander, M.N., Davalos, R.V. Theoretical Considerations of Tissue Electroporation With High-Frequency Bipolar Pulses IEEE Transactions on Biomedical Engineering 58 (5) 2011: pp. 1474-1482. https://doi.org/10.1109/TBME.2010.2102021

16. Al-Sakere, B., André, F., Bernat, C., Connault, E., Opolon, P., Davalos, R.V., Rubinsky, B., Mir, L.M. Tumor Ablation with Irreversible Electroporation Isalan M, ed. PLoS ONE 2 (11) 2007: pp. e1135.

17. Mir, L.M. Therapeutic Perspectives of in Vivo Cell Electropermeabilization Bioelectrochemistry 53 (1) 2001: pp. $1-10$.

18. Mir, L.M. Nucleic Acids Electrotransfer-Based Gene Therapy (Electrogenetherapy): Past, Current, and Future Molecular Biotechnology 43 (2) 2009: pp. 167-176. https://doi.org/10.1007/s12033-009-9192-6

19. Barsotti, L., Cheftel, J.C. Food Processing by Pulsed Electric Fields. II. Biological Aspects Food Reviews International 15 (2) 1999: pp. 181-213. https://doi.org/10.1080/87559129909541186

20. Miklavčič, D., Mali, B., Kos, B., Heller, R., Serša, G. Electrochemotherapy: From the Drawing Board into Medical Practice Biomedical Engineering Online 13 (1) 2014: pp. 29.

21. Miklavčič, D., Teissié, J., Neumann, E. BioElectroporation 2013 New Biotechnological and Clinical Applications Bioelectrochemistry (Amsterdam, Netherlands) 100 2014: pp. 1-2.

22. Wang, H.Y., Lu, C. High-Throughput and Real-Time Study of Single Cell Electroporation Using Microfluidics: Effects of Medium Osmolarity Biotechnology and Bioengineering 95 (6) 2006: pp. 1116-1125. https://doi.org/10.1002/bit.21066

23. Wang, M., Orwar, O., Olofsson, J., Weber, S.G. Singlecell Electroporation Analytical and Bioanalytical Chemistry 397 (8) 2010: pp. 3235-3248. https://doi.org/10.1007/s00216-010-3744-2 
24. Le Gac, S., van den Berg, A. Single Cell Electroporation using Microfluidic Devices Methods in Molecular Biology (Clifton, NJ) 853 2012: pp. 65-82. https://doi.org/10.1007/978-1-61779-567-1_7

25. Shahini, M., van Wijngaarden, F., Yeow, J.T.W. Fabrication of Electro-Microfluidic Channel for Single Cell Electroporation Biomedical Microdevices 15 (5) 2013: pp. $759-766$.

26. Fox, M.B., Esveld, D.C., Valero, A., Luttge, R., Mastwijk, H.C., Bartels, P.V., van den Berg, A., Boom, R.M. Electroporation of Cells in Microfluidic Devices: A Review Analytical and Bioanalytical Chemistry 385 (3) 2006: pp. 474-485.

https://doi.org/10.1007/s00216-006-0327-3

27. Durdík, Š., Krafčík, A., Babincová, M., Babinec, P. Conceptual Design of Integrated Microfluidic System for Magnetic Cell Separation, Electroporation, And Transfection Physica Medica: European Journal of Medical Physics 29 (5) 2013: pp. $562-567$.

28. Lee, Y., Deng, P. Review of Micro/Nano Technologies and Theories for Electroporation of Biological Cells Science China Physics, Mechanics and Astronomy 55 (6) 2012: pp. $996-1003$. https://doi.org/10.1007/s11433-012-4747-0

29. Wang, C.H., Lee, Y.H., Kuo, H.T., Liang, W.F., Li, W. J., Lee, G.B. Dielectrophoretically-assisted Electroporation Using Light-Activated Virtual Microelectrodes for Multiple DNA Transfection Lab Chip 14 (3) 2014: pp. 592-601. https://doi.org/10.1039/C3LC51102B

30. Li, Z., Wei, Z., Li, X., Du, Q., Liang, Z. Efficient and High-Throughput Electroporation Chips in: 2011 16th International Solid-State Sensors, Actuators and Microsystems Conference IEEE 2011:pp. 1825-1828. https://doi.org/10.1109/transducers.2011.5969892
31. Wei, Z., Huang, Y., Zhao, D., Liang, Z., Li, Z. A Parylene-Based Flexible Electroporation Chip Applicable for in Vivo Gene And Sirna Delivery in: 2011 16th International Solid-State Sensors, Actuators and Microsystems Conference IEEE 2011: pp. 1942-1945. https://doi.org/10.1109/transducers.2011.5969380

32. Luft, C., Ketteler, R. Electroporation Knows No Boundaries: The Use of Electrostimulation for siRNA Delivery in Cells and Tissues Journal of Biomolecular Screening 20 (8) 2015: pp. 932-942.

33. Tan, C.P., Craighead, H.G. Surface Engineering and Patterning Using Parylene for Biological Applications Materials 3 (3) 2010: pp. 1803-1832.

34. Zhou, YS., Wang, S., Yang, Y., Zhu, G., Niu, S., Lin, Z.H., Liu, Y., Wang, Z.L. Manipulating Nanoscale Contact Electrification by an Applied Electric Field Nano Letters 14 (3) 2014: pp. 1567-1572.

35. Chun, W., Chou, N., Cho, S., Yang, S., Kim, S. Evaluation of Sub-Micrometer Parylene C Films as an Insulation Layer Using Electrochemical Impedance Spectroscopy Progress in Organic Coatings 77 (2) 2014: pp. 537-547.

36. Noh, H.S., Huang, Y., Hesketh, P.J. Parylene Micromolding, a Rapid And Low-Cost Fabrication Method for Parylene Microchannel Sensors and Actuators B: Chemical 102 (1) 2004: pp. $78-85$.

37. Kuppusami, S., Oskouei, R.H. Parylene Coatings in Medical Devices and Implants: a Review Universal Journal of Biomedical Engineering 3 (2) 2015: pp. 9-14.

38. Novickij, V., Tabasnikov, A., Smith, S., Grainys, A., Novickij, J. Analysis of Planar Circular Interdigitated Electrodes for Electroporation IETE Technical Review 32 (3) 2015: pp. 196-203. 